\title{
PAK in pathogen-host interactions
}

\author{
Jean-Philippe Semblat ${ }^{1, *}$ and Christian Doerig ${ }^{2, *}$
}

${ }^{1}$ UMRS 665; Inserm/Université Paris Diderot; Paris, France; ${ }^{2}$ Department of Microbiology; School of Biomedical Sciences; Monash University; Clayton, VIC Australia

Keywords: p21-activated kinase, pathogen, Plasmodium, Helicobacter, Pseudomonas, HIV, influenza

Eukaryotic, prokaryotic and viral pathogens are known to interfere with signaling pathways of their host to promote their own survival and proliferation. Here, we present selected examples of modulation of PAK activity in human cells by both intracellular and extracellular pathogens, focusing on one eukaryotic pathogen, the human malaria parasite Plasmodium falciparum, two Gram-negative bacteria (Helicobacter pylori and Pseudomonas aeruginosa), and two viruses belonging to distinct groups, the lentivirus HIV and the orthomyxovirus Influenza virus $A$.

\section{Introduction: Subversion of Host Signaling by Pathogens}

Intracellular pathogens face many challenges to achieve proliferation and dissemination. They need first to enter the host cell, then create a niche inside the cell in order to mature and multiply, and their progeny must finally exit from the cell. Pathogenic bacteria and parasites have developed efficient secretion and translocation systems to export protein effectors into their host cell, where they manipulate host cell signaling for their own benefit. Likewise, viruses use the host cell gene expression machinery to produce a large variety of proteins that similarly divert host signaling pathways. There are even cases where virus-infected cells secrete viral proteins to the extracellular medium, from which they are taken up by bystander cells where they subvert signaling pathways; for example, cells infected by the human immunodeficiency virus HIV secrete the virally-encoded Tat and Nef proteins, which find their way into bystander lymphocyte to modulate the immune response. ${ }^{1,2}$ Many pathogens that remain extracellular also manipulate cells of their host organism, through complex secretion systems such as type 3 and 4 secretion systems (T3SS and T4SS), that allow them to directly transfer toxins and effectors across their own membranes and that of the target cell, and which are major virulence factors (reviewed in refs. 3 and 4).

During these processes, host cells are subject to important modifications such as membrane modifications or reorganization of the cytoskeleton. The challenge is to manipulate the host cell for its own benefit and maintaining the cell alive until the

*Correspondence to: Jean-Philippe Semblat and Christian Doerig; Email: jean-philippe.semblat@inserm.fr and christian.doerig@monash.edu Submitted: 02/27/12; Revised: 03/22/12; Accepted: 03/30/12 http://dx.doi.org/10.4161/cl.20222 pathogen escape and can invade a new cell. One of the main defense mechanisms developed by mammalian cells against intracellular pathogens is the induction of apoptosis. To ensure survival of their host for the duration of their own maturation, intracellular pathogens must block apoptosis, induction of which is in many instances triggered by the trauma that breaking in of the pathogen causes. Many intracellular pathogens achieve this through inhibition of the NFKB pathway. Yersinia pestis, the agent responsible for the plague disease, secrete a protein called YopP that prevents ubiquitination of $I \kappa B$, a protein that sequesters and thus inhibits the $\mathrm{\kappa B}$ transcription factor, thereby blocking the expression of pro-apoptotic genes. ${ }^{5}$ Other host cell signaling pathways targeted by pathogens are those implicating MAPKs (mitogen-activated protein kinases). Bacillus anthracis, for example secretes a metalloproteinase toxin called lethal factor (LF) that cleaves the $\mathrm{N}$-terminal extension of MAPKK (MAP kinase kinase). Once the kinase is cleaved, MKK cannot interact anymore with its substrate. ${ }^{6}$ Inactivation of the MAPK pathway by LF factor leads to impairment of innate and adaptive immunity.

In the following sections, we will consider selected examples of eukaryotic (the malaria parasite Plasmodium falciparum), prokaryotic (the bacteria Helicobacter pylori and Pseudomonas aeruginosa) and viral (HIV and influenza virus) pathogens that interfere with PAK signaling to promote their survival and proliferation in their host.

\section{Activation of a Host Cell PAK-MEK Pathway in Malaria Parasite-Infected Erythrocytes}

Malaria remains one of the most devastating infectious diseases, claiming the lives of close to one million persons every year, most of whom are young children in sub-Saharan Africa. The agent responsible for the most severe form of human malaria is Plasmodium falciparum, an intracellular parasite of belonging to the phylum Apicomplexa. Transmitted to the human host through the bite of an infected Anopheles mosquito, the parasite quickly reaches the liver and invades a hepatocyte, where a first round of (asymptomatic) asexual multiplication (exo-erythrocytic schizogony) requires seven days to reach completion. In order to maintain survival of its host hepatocyte for that duration, the parasite interferes with the NFKB pathway, thereby preventing apoptosis. $^{7,8}$ This is not the only host cell pathway that is tampered with by the parasite. A kinome-wide RNAi study identified five host protein kinases implicated in hepatocyte infection by the rodent malaria Plasmodium berghei, " and indicated that PAK3 inhibition leads to a reduction in parasite 
infection. Further specific investigations would be required to confirm the role of host hepatocyte PAK3 during Plasmodium development.

Following hepatocyte rupture, free malaria parasites (merozoites) invade red blood cells and initiate cycles of asexual multiplication (erythrocytic schizogony) that are responsible for malaria pathogenesis. Each cycle consists of a succession of developmental stage, starting with the so-called ring stage that immediately follows invasion (named after the shape of the intracellular parasite in Giemsa-stained blood smears), followed by the trophozoite stage during which the parasite grows by feeding largely on host cell hemoglobin, and finally the schizont stage, that is defined as the multi-nucleated parasite resulting from multiple nuclear divisions prior to cytokinesis and merozoite release. During the invasion process, a parasitophorous vacuole (PV) is formed, inside which the parasite will reside during its development in the red blood cell. Maturation of the parasite in the erythrocyte results in an important reorganization of the red blood cell cytoskeleton, ${ }^{10}$ and the infected erythrocyte becomes spherical and rigid. Such a red cell would be eliminated by the spleen if the parasite had not developed a strategy to adhere to endothelial cells and be sequestered from the circulation, thus avoiding the spleen. ${ }^{11}$ During parasite maturation, numerous Plasmodium proteins are exported to the cytosol or the plasma membrane of the host erythrocyte through a specific translocon located at the PV membrane; ${ }^{12}$ these include the variant antigens of the PfEMP1 family that mediate cyto-adhesion ${ }^{13}$ ). Conversely, it has recently been shown that the parasite imports a host cell protein (peroxiredoxin II), ${ }^{14}$ and this may occur for many other host cell proteins. Such protein trafficking is indicative of intimate molecular interactions between parasite and host cell. Moreover, host erythrocyte signaling is essential for malaria parasite entry and maturation. Indeed, blocking GPCR (G protein-coupled receptors) and heterotrimeric $G$ proteins signaling inhibit Plasmodium entry and development in the red blood cell. ${ }^{15,16}$ Another signaling molecule, the host erythrocyte protein kinase $\mathrm{C}$ (PKC), is activated upon P. falciparum infection, ${ }^{17}$ although the physiological significance of this observation has not been established.

An extensive investigation of host erythrocyte signaling events triggered during Plasmodium proliferation has been made difficult by the impossibility of performing reverse genetics and RNAi approaches in a mature red blood cell. Pharmacological interference represents an alternative route of investigation, and implementing this approach led to the observation that several structurally distinct, highly selective MEK inhibitors block parasite development at the trophozoite stage, and that under MEK inhibitor treatment, parasite DNA replication was severely impaired. ${ }^{18}$ At the time these initial experiments were performed, it was thought that the target was a parasite-encoded MEK; however, subsequent availability of the $P$. falciparum genome sequence $^{19}$ and in silico characterization of the parasite's kinome revealed the absence of genes encoding MEK homologs in the plasmodial genome. ${ }^{20,21}$ This suggested the intriguing possibility that the inhibitors exerted their effect through inhibition of a host erythrocyte MEK. Consistent with this hypothesis, it was found that human MEK1 was phosphorylated on Ser298 in infected erythrocytes, but not (or to very low levels) in uninfected erythrocytes. Ser298 phosphorylation is known to promote MEK1 activation, and PAK is the only kinase described so far to phosphorylate MEK on this residue. ${ }^{22,23}$ As expected, phosphorylation of PAK on Ser141 was higher in P. falciparuminfected erythrocytes than in uninfected erythrocytes. Furthermore, incubation of $P$. falciparum cultures with the chemical PAK inhibitor IPA- $3^{24}$ blocked parasite maturation and multiplication and reduced phosphorylation of MEK at serine $298{ }^{18}$ Taken together, these data indicate that a host erythrocyte PAK-MEK pathway is activated by $P$. falciparum infection (Fig. 1). However, several questions remain:

First, how is PAK activated? In view of the implication of heterotrimeric $\mathrm{G}$ proteins in erythrocyte infection, it is attractive to speculate that they are involved in the process; however, the parasite exports a large number of proteins (including protein kinases) to the erythrocyte (see above), and triggering of the PAKMEK pathway may result from the activity of such parasiteencoded proteins present in the erythrocyte cytoplasm.

Second, what are the effectors of the PAK-MEK pathway, and why is parasite development blocked by MEK or PAK inhibitors? An attractive hypothesis is that the pathway is responsible for activation of the new permeation pathways (NPP) that characterize infected erythrocytes, and that allow intake of nutrients that are essential for parasite growth into the infected cell. $^{25}$ Many eukaryotic transporters are indeed positively regulated by phosphorylation. ${ }^{26}$ Interestingly, it appears that ERK1/2, the only known substrates of MEK in eukaryotic cells, are not hyper-phosphorylated in Plasmodium-infected compared with uninfected erythrocytes, ${ }^{18}$ and that alternative substrate(s) may be used by the enzyme in this system.

Third, what are the roles of host PAK homologs during Plasmodium erythrocyte infection? It is likely, considering the multiple functions of PAK in other cell systems, that the role of the enzyme(s) is not restricted to phosphorylation of MEK on Ser278. For example, PAK is known for its role in cytoskeletal reorganization (reviewed in ref. 27). One can hypothesize that PAK participates in the extensive reorganization of the erythrocyte cytoskeleton that occurs during invasion and parasite maturation.

\section{Pathogenic Bacteria and PAK-Selected Examples}

Helicobacter pylori. Helicobacter pylori is a Gram-negative, microaerophilic bacterium found in the stomach, where it adheres at the surface of epithelial cells. More than 50\% of the world's population harbor $H$. pylori in their upper gastrointestinal tract but over $80 \%$ of infected individuals show no symptoms. H. pylori bacteria are present in patients with chronic gastritis, gastric ulcers and gastric carcinoma. ${ }^{28,29}$ Between 50 and $60 \%$ of H. pylori isolates possess a DNA segment called the CagA pathogenicity island (PAI; reviewed in ref. 30). Patients infected with strains carrying the cag PAI display a stronger inflammatory response in the stomach and are at a greater risk of developing peptic ulcers or stomach cancer than those infected with strains 


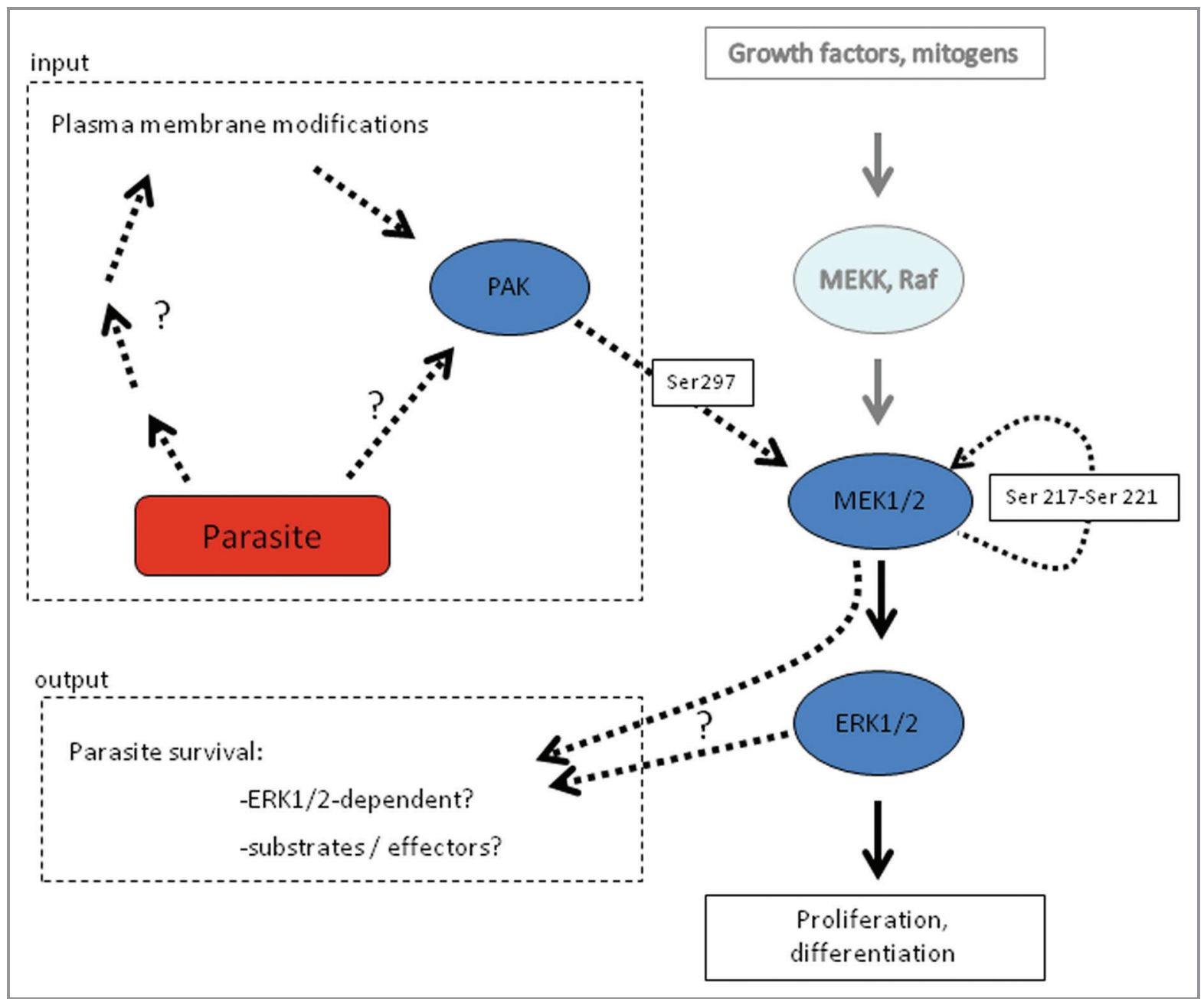

Figure 1. Hijacking of the host erythrocyte MAPK pathway by the malaria parasite Plasmodium falciparum. Infection of the erythrocyte by $P$. falciparum results in the activation of a PAK-MEK pathway in the host cell. To the right, the canonical MEKK-MEK-MAPK is depicted. As indicated to the left, parasite infection results in PAK activation, through mechanisms that remain to be elucidated. This leads to PAK-dependent phosphorylation of MEK1 on S298, an event known to cause auto-phosphorylation of MEK1 on its activation loop (Ser 217-221), and hence activation of MEK1. The effectors of the pathway also remain to be determined, although it is known that interference with PAK or MEK function blocks parasite development. See text for details.

lacking the island; ${ }^{31}$ infection with CagA-positive $H$. pylori is the strongest risk factor for gastric carcinoma. ${ }^{32}$

H. pylori infection leads to a profound reorganization of the host cell cytoskeleton, with actin polymerization and ruffle-like structures appearing at the cell periphery. ${ }^{33}$ After cagA-positive $H$. pylori adheres to gastric epithelial cells, the CagA protein is translocated into gastric epithelial cells through a type IV secretion system. ${ }^{34}$ Inside the cell, CagA is tyrosine phosphorylated and stimulates many signaling pathways. ${ }^{35}$ One of its effects is activation of the small Rho GTPases Rac1 and Cdc42, leading to the activation of PAK1 $1{ }^{36} \mathrm{~A}$ different study described the role of $\alpha$-Pix (PAK-interactive exchange factor), a PAK-binding protein know to represent strong PAK activators. ${ }^{33}$ Phosphorylated CagA leads to dephosphorylation of $\alpha$-Pix and may thereby modulate cytoskeletal changes in gastric epithelial cells through PAK regulation. ${ }^{37}$ Moreover, down-regulation of $\alpha$-Pix through an siRNA approach resulted in the absence of PAK activation by CagA. ${ }^{38}$ These authors also demonstrated that ERK and NFKB signaling pathways are downstream targets of $\alpha$-Pix. Additionally, $\alpha$-Pix siRNA suppressed IL-8 induction after translocation of CagA into the cells, indicating that IL-8 expression is dependent on the CagA- $\alpha$-Pix interaction. ${ }^{38} \mathrm{H}$. pylori infection leads to an important proinflammatory response induced mainly by the interleukin-1 beta (IL-1 $\beta$ ) cytokine. H. pylori lipopolysaccharide (LPS) induced direct interaction between PAK1 and caspase-1 (a protease that is required for the maturation of pro-IL-1 $\beta$ into the active cytokine), and immunoprecipitated PAK1 from lysates of H. pylori LPS-challenged cells was able to phosphorylate recombinant caspase-1. These data indicate that upon $H$. pylori LPS induction, activated PAK stimulates IL-1 production ${ }^{39}$ and therefore plays a major role in the inflammatory response that is one of the hallmarks of $H$. pylori pathogenesis.

Pseudomonas aeruginosa. Pseudomonas aeruginosa, a Grampositive aerobic bacteria found in soil and aquatic environment, is an opportunistic human pathogen that represents a major cause of nosocomial infection in humans, causing severe 
infection of the respiratory and urinary tract, skin and eye in immunocompromised hosts or in patients with lesions in these tissues; it is responsible for lethal pulmonary infection in most cystic fibrosis (CF) subjects (reviewed in ref. 40). P. aeruginosainduced lung inflammation involves binding to airway cells and subsequent direct and indirect cytotoxic effects. ${ }^{41}$ Bacterial internalization is a possible result of bacteria-lung epithelial cell interaction. ${ }^{42} P$. aeruginosa possesses an extensive secretion machinery, including a type III secretion system used to secrete the ExoU, ExoY, ExoS and ExoT effectors into target cells; these proteins subvert host cell functions, leading to actin cytoskeleton rearrangement, a crucial step for subsequent internalization of the bacteria (reviewed in ref. 43). ExoS and ExoT contain N-terminal GTPase activating protein (GAP) domains targeting Rho family GTPases such as Rho, Rac1 and Cdc42, ${ }^{44-46}$ the latter two being well-established activators of PAK. An RNAi screen approach revealed host cell molecules Abl1, Rac1 and Cdc42, and PAK1 as being essential for internalization of $P$. aeruginosa. The absence of additive effect when depleting both Abl1 and PAK1 suggest that Abl1 and Pak1 belong to the same pathway. ${ }^{47}$ In contrast, PAK1 inhibition had no effect on bacterial adhesion. ${ }^{48}$ Expression of a constitutively active mutant as well as a kinase-dead mutant of Pak1 inhibited bacterial internalization, ${ }^{47}$ consistent with the proposition that oscillation of the kinase between an active and inactive state is required for its function. ${ }^{49}$ The Arp $2 / 3$ complex, a major regulator of actin polymerisation, is also required in $P$. aeruginosa invasion, ${ }^{47}$ and may be one of the effectors of PAK1 function in the process.

\section{Viruses and PAK: Selected Examples}

HIV. UNAIDS and the WHO estimated that AIDS (acquired immune deficiency syndrome) killed more than 25 million people between 1981 and 2005, making it one of the most destructive pandemics in recorded history. Around 30 million people are infected worldwide and there are 3 million new infections each year. AIDS is caused by the HIV retrovirus, which infects cells that play crucial roles in the human immune system, such as helper $\mathrm{T}$ cells (specifically $\mathrm{CD}^{+} \mathrm{T}$ cells), macrophages, and dendritic cells. ${ }^{34}$ When $\mathrm{CD}^{+}{ }^{+} \mathrm{T}$ cell numbers decline below a critical threshold of 200 cells per $\mu \mathrm{L}$, cell-mediated immunity is lost, exposing the patient to a wide variety of opportunistic microbial infections. Thus, the major causes of AIDS patients' death are deadly infection by a variety of pathogenic bacteria/ fungi or tumor viruses, mainly due to the loss of their immune system. Although treatments for HIV/AIDS can slow-down the course of the disease, there is no known cure or HIV vaccine. Anti-retroviral treatment reduces both the deaths and new infections from HIV/AIDS, but these drugs are expensive and the medications are not available in a number of developing African and South-Asian countries. Due to the difficulty in treating HIV infection, preventing infection is a key aim in controlling the AIDS pandemic, with health organizations promoting "safe sex" and "no needle-exchange" programs in attempts to slow the spread of this virus. However, once people are contracted with HIV, both effective and relatively inexpensive therapeutics are desired to become available for the treatment of HIV infection.

The Nef (negative factor) is a critical viral protein responsible for AIDS pathogenesis. ${ }^{50,51} \mathrm{Nef}$ is implicated in many aspect of the virus life cycle such as replication, spread and immune evasion. First called NAK for Nef-associated kinase, a serine kinase encoded by the host cell was found to be associated with Nef. ${ }^{51}$ The kinase was later identified by several research groups as PAK. ${ }^{28,52,53}$ Wolf et al. described the activation of PAK by Nef via a phosphatidylinositol-3 kinase (PI3-kinase) pathway, leading to stimulation of $\mathrm{BAD}(\mathrm{Bcl} 2$ antagonist of cell death, a member of the Bcl family) phosphorylation at serine $112 .{ }^{54}$ As the phosphorylation of BAD at serine 112 has an anti-apoptotic effect, it is likely that the virus uses this strategy to block the apoptotic signals triggered by its presence in the cell. Interestingly, this result is consistent with the finding that Nef activates PAK by recruiting the kinase at the lipid raft fraction of the membrane. ${ }^{37}$ Indeed, it is known that BAD possesses two lipid binding domains ${ }^{55}$ and can be regulated through its attachment to the lipid rafts. ${ }^{56-58}$ Which member of the PAK family is binding Nef is still a subject to debate. The original school of thought favored PAK2 as the Nef-binding PAK isoform. ${ }^{29,59}$ In 2006 however, based on a siRNA approach, Nguyen et al. demonstrated that PAK1 but not PAK2 inhibition strongly reduced HIV infection in multiple cell systems, suggesting that PAK1 is the Nef partner during the virus infection, even if no direct demonstration that PAK1 is binding Nef was provided. ${ }^{60}$ One can envisage that both PAK1 and PAK2 are important for the virus pathogenicity, with each protein having a distinct function.

Influenza virus. Propolis, a plant mixture collected and processed by bees, has been used to prevent or treat flu influenza infection since the ancient Egyptian era. However, the mode of action of propolis was totally unknown until the recent observation that propolis contains a variety of PAK1-blockers such as caffeic acid phenethyl ester, apigenin and Artepilin C, that impact a variety of solid tumors such as pancreatic and colon cancers, all of which require PAK1 for their growth and metastasis $^{61-63}$ (for detail, see the previous and next papers in this issue). Since PAK1 has been implicated in the replication of several viruses including HIV, a Korean group led by Young-Ki Choi started testing first if replication of the influenza $A$ virus stimulated the auto-phosphorylation of PAK1, and showed that this is indeed the case. ${ }^{64}$ Moreover, transfection of a constitutively active form of PAK1 (rendered active through the phosphomimetic T423E mutation) in A549 cells induced -10 -fold higher viral titers compared with those observed after transfection of the control vector or of a plasmid expressing a kinase-dead K299R mutant PAK1. Furthermore, PAK1-specific siRNA knockdown reduced the virus yield by $10-100$-fold, and treatment with TATPAK18, a cell permeable anti-PAK1 peptide, suppresses both ERK 1/2 phosphorylation and infectious virus production, as does U0126, a specific MEK/ERK inhibitor. These findings clearly indicate that like malaria and HIV infection, the infection with influenza virus activates PAK1 in host cells, which is essential for robust replication of the pathogen. ${ }^{64}$ The pathway leading to PAK activation during viral infection remains to be elucidated. 


\section{Concluding Remarks}

Pathogens are able to modify their environment (the host) to promote completion of their maturation and multiplication. Intracellular pathogens such as malaria parasites and viruses, as well as several bacteria, can affect signaling in their host cell, whereas extracellular pathogens have evolved a variety of secretion systems allowing them to translocate effectors into neighboring cells to which they adhere. Since PAK isoforms are involved in many cellular functions, including dynamics of the cytoskeleton (which must be reorganized in a number of host-pathogen interactions), it is no wonder that intracellular pathogens target kinases of this family, notably with respect to the host cell invasion process. This offers opportunities in two areas: first, it can provide new perspectives in fundamental investigations of signaling pathways of mammalian cells. Studying transduction pathways in a cell infected by a pathogen provides an original angle of approach to elucidate signaling cascades and may help to reveal new triggers and downstream effectors of such pathways, as well as cross-talk between established pathways. Second, it opens perspectives for novel perspectives in anti-infectious chemotherapeutic strategies.
Targeting host enzymes that are required for survival of a pathogenic organism would deprive the infectious agent of a major modus operandi for development of drug resistance, namely the selection of mutations in the target-encoding gene that confer direct adaptive advantage under drug treatment. Therefore, targeting host cell molecules involved in the pathogen development represents an approach that would drastically reduce the risk of drug resistance. Another potential benefit of this approach, especially with respect to infectious diseases that affect primarily the developing world and which have been largely neglected in the past for market-driven reasons, is that it may allow piggy-backing on compounds developed against human kinases in the context of pathologies such as cancer. Indeed, protein kinases are a major target class in current anticancer drug discovery, and several kinase inhibitors have been approved for cancer therapy in the last decade.

\section{Acknowledgments}

We thank Prof. Hiroshi Maruta for suggesting this review, for his insightful suggestions, notably relating to the sections on bacteria and viruses, and for his critical comments on the manuscript.

\section{References}

1. Muratori C, Cavallin LE, Krätzel K, Tinari A, De Milito A, Fais S, et al. Massive secretion by $\mathrm{T}$ cells is caused by HIV Nef in infected cells and by Nef transfer to bystander cells. Cell Host Microbe 2009; 6:218-30; PMID:19748464; http://dx.doi.org/10.1016/j.chom. 2009.06.009

2. Mangino G, Percario ZA, Fiorucci G, Vaccari G, Manrique S, Romeo $G$, et al. In vitro treatment of human monocytes/macrophages with myristoylated recombinant Nef of human immunodeficiency virus type 1 leads to the activation of mitogen-activated protein kinases, IkappaB kinases, and interferon regulatory factor 3 and to the release of beta interferon. J Virol 2007; 81:2777-91; PMID:17182689; http://dx. doi.org/10.1128/JVI.01640-06

3. Izoré T, Job V, Dessen A. Biogenesis, regulation, and targeting of the type III secretion system. Structure 2011; 19:603-12; PMID:21565695; http://dx.doi.org/ 10.1016/j.str.2011.03.015

4. Voth DE, Broederdorf LJ, Graham JG. Bacterial Type IV secretion systems: versatile virulence machines. Future Microbiol 2012; 7:241-57; PMID:22324993; http://dx.doi.org/10.2217/fmb.11.150

5. Adkins I, Schulz S, Borgmann S, Autenrieth IB, Gröbner S. Differential roles of Yersinia outer protein P-mediated inhibition of nuclear factor-kappa B in the induction of cell death in dendritic cells and macrophages. J Med Microbiol 2008; 57:139-44; PMID: 18201977; http://dx.doi.org/10.1099/jmm.0.47437-0

6. Duesbery NS, Webb CP, Leppla SH, Gordon VM, Klimpel KR, Copeland TD, et al. Proteolytic inactivation of MAP-kinase-kinase by anthrax lethal factor. Science 1998; 280:734-7; PMID:9563949; http://dx. doi.org/10.1126/science.280.5364.734

7. Singh AP, Buscaglia CA, Wang Q, Levay A, Nussenzweig DR, Walker JR, et al. Plasmodium circumsporozoite protein promotes the development of the liver stages of the parasite. Cell 2007; 131:492504; PMID:17981117; http://dx.doi.org/10.1016/j. cell.2007.09.013

8. van de Sand C, Horstmann S, Schmidt A, Sturm A, Bolte S, Krueger A, et al. The liver stage of Plasmodium berghei inhibits host cell apoptosis. Mol Microbiol 2005; 58:731-42; PMID:16238623; http://dx.doi.org/ 10.1111/j.1365-2958.2005.04888.x
9. Prudêncio $M$, Rodrigues $C D$, Hannus $M$, Martin C, Real E, Gonçalves LA, et al. Kinome-wide RNAi screen implicates at least 5 host hepatocyte kinases in Plasmodium sporozoite infection. PLoS Pathog 2008; 4:e1000201; PMID:18989463; http://dx.doi.org/10. 1371/journal.ppat.1000201

10. Haldar K, Mohandas N. Erythrocyte remodeling by malaria parasites. Curr Opin Hematol 2007; 14:203-9; PMID:17414208; http://dx.doi.org/10.1097/MOH. 0b013e3280f31b2d

11. Buffet PA, Safeukui I, Deplaine G, Brousse V, Prendki V, Thellier M, et al. The pathogenesis of Plasmodium falciparum malaria in humans: insights from splenic physiology. Blood 2011; 117:381-92; PMID:20852127; http://dx.doi.org/10.1182/blood-2010-04-202911

12. de Koning-Ward TF, Gilson PR, Boddey JA, Rug M, Smith BJ, Papenfuss AT, et al. A newly discovered protein export machine in malaria parasites. Nature 2009; 459:945-9; PMID:19536257; http://dx.doi.org/ 10.1038/nature08104

13. Scherf A, Lopez-Rubio JJ, Riviere L. Antigenic variation in Plasmodium falciparum. Annu Rev Microbiol 2008; 62:445-70; PMID:18785843; http://dx.doi.org/10. 1146/annurev.micro.61.080706.093134

14. Koncarevic S, Rohrbach P, Deponte M, Krohne G, Prieto JH, Yates J, 3rd, et al. The malarial parasite Plasmodium falciparum imports the human protein peroxiredoxin 2 for peroxide detoxification. Proc Nat Acad Sci U S A 2009; 106:13323-8; PMID:19666612; http://dx.doi.org/10.1073/pnas.0905387106

15. Harrison T, Samuel BU, Akompong T, Hamm H, Mohandas N, Lomasney JW, et al. Erythrocyte G protein-coupled receptor signaling in malarial infection. Science 2003; 301:1734-6; PMID:14500986; http:// dx.doi.org/10.1126/science.1089324

16. Murphy SC, Harrison T, Hamm HE, Lomasney JW, Mohandas N, Haldar K. Erythrocyte G protein as a novel target for malarial chemotherapy. PLoS Med 2006; 3:e528; PMID:17194200; http://dx.doi.org/10. 1371/journal.pmed.0030528

17. Hall BS, Daramola OO, Barden G, Targett GA. Modulation of protein kinase $\mathrm{C}$ activity in Plasmodium falciparum-infected erythrocytes. Blood 1997; 89:17708; PMID:9057662
18. Sicard A, Semblat JP, Doerig C, Hamelin R, Moniatte M, Dorin-Semblat D, et al. Activation of a PAK-MEK signalling pathway in malaria parasite-infected erythrocytes. Cell Microbiol 2011; 13:836-45; PMID: 21371233; http://dx.doi.org/10.1111/j.1462-5822. 2011.01582.x

19. Gardner MJ, Hall N, Fung E, White O, Berriman M, Hyman RW, et al. Genome sequence of the human malaria parasite Plasmodium falciparum. Nature 2002; 419:498-511; PMID:12368864; http://dx.doi.org/10. 1038/nature01097

20. Ward P, Equinet L, Packer J, Doerig C. Protein kinases of the human malaria parasite Plasmodium falciparum: the kinome of a divergent eukaryote. BMC Genomics 2004; 5:79; PMID:15479470; http://dx.doi.org/10. 1186/1471-2164-5-79

21. Anamika SN, Srinivasan N, Krupa A. A genomic perspective of protein kinases in Plasmodium falciparum. Proteins 2005; 58:180-9; PMID:15515182; http://dx.doi.org/10.1002/prot.20278

22. Park ER, Eblen ST, Catling AD. MEK1 activation by PAK: a novel mechanism. Cell Signal 2007; 19:1488-96; PMID:17314031; http://dx.doi.org/10.1016/j.cellsig. 2007.01.018

23. Slack-Davis JK, Eblen ST, Zecevic M, Boerner SA, Tarcsafalvi A, Diaz HB, et al. PAK1 phosphorylation of MEK1 regulates fibronectin-stimulated MAPK activation. J Cell Biol 2003; 162:281-91; PMID:12876277; http://dx.doi.org/10.1083/jcb.200212141

24. Deacon SW, Beeser A, Fukui JA, Rennefahrt UE, Myers C, Chernoff J, et al. An isoform-selective, small-molecule inhibitor targets the autoregulatory mechanism of p21activated kinase. Chem Biol 2008; 15:322-31; PMID: 18420139; http://dx.doi.org/10.1016/j.chembiol.2008. 03.005

25. Staines HM, Ellory JC, Chibale K. The new permeability pathways: targets and selective routes for the development of new antimalarial agents. Comb Chem High Throughput Screen 2005; 8:81-8; PMID:15720199; http://dx.doi.org/10.2174/1386207053328138 
26. Stolarczyk EI, Reiling CJ, Paumi CM. Regulation of $\mathrm{ABC}$ transporter function via phosphorylation by protein kinases. Curr Pharm Biotechnol 2011; 12:621-35; PMID:21118091; http://dx.doi.org/10. 2174/138920111795164075

27. Chan PM, Manser E. PAKs in human disease. Prog Mol Biol Transl Sci 2012; 106:171-87; PMID: 22340718; http://dx.doi.org/10.1016/B978-0-12396456-4.00011-0

28. Lu X, Wu X, Plemenitas A, Yu H, Sawai ET, Abo A, et al. CDC42 and Rac1 are implicated in the activation of the Nef-associated kinase and replication of HIV-1. Curr Biol 1996; 6:1677-84; PMID:8994833; http:// dx.doi.org/10.1016/S0960-9822(02)70792-6

29. Arora VK, Molina RP, Foster JL, Blakemore JL, Chernoff J, Fredericksen BL, et al. Lentivirus Nef specifically activates Pak2. J Virol 2000; 74:11081-7; PMID:11070003; http://dx.doi.org/10.1128/JVI.74. 23.11081-11087.2000

30. Sibony M, Jones NL. Recent advances in Helicobacter pylori pathogenesis. Curr Opin Gastroenterol 2012; 28:30-5; PMID:22157439; http://dx.doi.org/10.1097/ MOG.0b013e32834dda51

31. Kusters JG, van Vliet AH, Kuipers EJ. Pathogenesis of Helicobacter pylori infection. Clin Microbiol Rev 2006; 19:449-90; PMID:16847081; http://dx.doi.org/ 10.1128/CMR.00054-05

32. Liu Z, Xu X, Chen L, Li W, Sun Y, Zeng J, et al. Helicobacter pylori CagA inhibits the expression of Runx3 via Src/MEK/ERK and p38 MAPK pathways in gastric epithelial cell. J Cell Biochem 2012; 113:10806; PMID:22266963; http://dx.doi.org/10.1002/jcb. 23440

33. Baek HY, Lim JW, Kim H. Interaction between the Helicobacter pylori CagA and alpha-Pix in gastric epithelial AGS cells. Ann N Y Acad Sci 2007; 1096:1823; PMID:17405911; http://dx.doi.org/10.1196/ annals. 1397.065

34. Cunningham AL, Donaghy H, Harman AN, Kim M, Turville SG. Manipulation of dendritic cell function by viruses. Curr Opin Microbiol 2010; 13:524-9; PMID: 20598938; http://dx.doi.org/10.1016/j.mib.2010.06. 002

35. Segal ED, Cha J, Lo J, Falkow S, Tompkins LS. Altered states: involvement of phosphorylated CagA in the induction of host cellular growth changes by Helicobacter pylori. Proc Natl Acad Sci U S A 1999; 96:14559-64; PMID:10588744; http://dx.doi.org/10. 1073/pnas.96.25.14559

36. Churin Y, Kardalinou E, Meyer TF, Naumann M. Pathogenicity island-dependent activation of Rho GTPases Rac1 and Cdc42 in Helicobacter pylori infection. Mol Microbiol 2001; 40:815-23; PMID: 11401689; http://dx.doi.org/10.1046/j.1365-2958. 2001.02443.x

37. Krautkrämer E, Giese SI, Gasteier JE, Muranyi W, Fackler OT. Human immunodeficiency virus type 1 Nef activates p21-activated kinase via recruitment into lipid rafts. J Virol 2004; 78:4085-97; PMID: 15047825; http://dx.doi.org/10.1128/JVI.78.8.40854097.2004

38. Lim JW, Kim KH, Kim H. alphaPix interacts with Helicobacter pylori CagA to induce IL-8 expression in gastric epithelial cells. Scand J Gastroenterol 2009; 44:1166-72; PMID:19672789; http://dx.doi.org/10. 1080/00365520903144398

39. Basak C, Pathak SK, Bhattacharyya A, Mandal D, Pathak S, Kundu M. NF-kappaB- and C/EBPbetadriven interleukin-1beta gene expression and PAK1mediated caspase-1 activation play essential roles in interleukin-1beta release from Helicobacter pylori lipopolysaccharide-stimulated macrophages. J Biol Chem 2005; 280:4279-88; PMID:15561713; http:// dx.doi.org/10.1074/jbc.M412820200
40. Hassett DJ, Sutton MD, Schurr MJ, Herr AB, Caldwell CC, Matu JO. Pseudomonas aeruginosa hypoxic or anaerobic biofilm infections within cystic fibrosis airways. Trends Microbiol 2009; 17:130-8; PMID:19231190; http://dx.doi.org/10.1016/j.tim.2008.12.003

41. Pier GB, Grout M, Zaidi TS, Olsen JC, Johnson LG, Yankaskas JR, et al. Role of mutant CFTR in hypersusceptibility of cystic fibrosis patients to lung infections. Science 1996; 271:64-7; PMID:8539601; http://dx.doi.org/10.1126/science.271.5245.64

42. Plotkowski MC, de Bentzmann S, Pereira SH, Zahm JM, Bajolet-Laudinat O, Roger P, et al. Pseudomonas aeruginosa internalization by human epithelial respiratory cells depends on cell differentiation, polarity, and junctional complex integrity. Am J Respir Cell Mol Biol 1999; 20:880-90; PMID:10226058

43. Filloux A. Protein Secretion Systems in Pseudomonas aeruginosa: An Essay on Diversity, Evolution, and Function. Front Microbiol 2011; 2:155; PMID: 21811488; http://dx.doi.org/10.3389/fmicb.2011.00155

44. Goehring UM, Schmidt G, Pederson KJ, Aktories K, Barbieri JT. The N-terminal domain of Pseudomonas aeruginosa exoenzyme $S$ is a GTPase-activating protein for Rho GTPases. J Biol Chem 1999; 274:36369-72; PMID:10593930; http://dx.doi.org/10.1074/jbc.274. 51.36369

45. Krall R, Schmidt G, Aktories K, Barbieri JT. Pseudomonas aeruginosa ExoT is a Rho GTPaseactivating protein. Infect Immun 2000; 68:6066-8; PMID:10992524; http://dx.doi.org/10.1128/IAI.68. 10.6066-6068.2000

46. Kazmierczak BI, Engel JN. Pseudomonas aeruginosa ExoT acts in vivo as a GTPase-activating protein for RhoA, Rac1, and Cdc42. Infect Immun 2002; 70:2198-205; PMID:11895987; http://dx.doi.org/10. 1128/IAI.70.4.2198-2205.2002

47. Pielage JF, Powell KR, Kalman D, Engel JN. RNAi screen reveals an Abl kinase-dependent host cell pathway involved in Pseudomonas aeruginosa internalization. PLoS Pathog 2008; 4:e1000031; PMID:18369477; http://dx.doi.org/10.1371/journal.ppat.1000031

48. Kazmierczak BI, Mostov K, Engel JN. Epithelial cell polarity alters Rho-GTPase responses to Pseudomonas aeruginosa. Mol Biol Cell 2004; 15:411-9; PMID: 14595106; http://dx.doi.org/10.1091/mbc.E03-080559

49. Zegers MM, Forget MA, Chernoff J, Mostov KE, ter Beest MB, Hansen SH. Pak1 and PIX regulate contact inhibition during epithelial wound healing. EMBO J 2003; 22:4155-65; PMID:12912914; http://dx.doi. org/10.1093/emboj/cdg398

50. Foster JL, Garcia JV. HIV-1 Nef: at the crossroads. Retrovirology 2008; 5:84; PMID:18808677; http://dx. doi.org/10.1186/1742-4690-5-84

51. Sawai ET, Baur A, Struble H, Peterlin BM, Levy JA, Cheng-Mayer C. Human immunodeficiency virus type 1 Nef associates with a cellular serine kinase in $\mathrm{T}$ lymphocytes. Proc Natl Acad Sci U S A 1994; 91:153943; PMID:8108442; http://dx.doi.org/10.1073/pnas. 91.4 .1539

52. Nunn MF, Marsh JW. Human immunodeficiency virus type $1 \mathrm{Nef}$ associates with a member of the p21activated kinase family. J Virol 1996; 70:6157-61; PMID:8709241

53. Sawai ET, Khan IH, Montbriand PM, Peterlin BM, Cheng-Mayer C, Luciw PA. Activation of PAK by HIV and SIV Nef: importance for AIDS in rhesus macaques. Curr Biol 1996; 6:1519-27; PMID:8939608; http:// dx.doi.org/10.1016/S0960-9822(96)00757-9
54. Wolf D, Witte V, Laffert B, Blume K, Stromer E, Trapp S, et al. HIV-1 Nef associated PAK and PI3kinases stimulate Akt-independent Bad-phosphorylation to induce anti-apoptotic signals. Nat Med 2001; 7:1217-24; PMID:11689886; http://dx.doi.org/10. 1038/nm1101-1217

55. Hekman M, Albert S, Galmiche A, Rennefahrt UE, Fueller J, Fischer A, et al. Reversible membrane interaction of $\mathrm{BAD}$ requires two $\mathrm{C}$-terminal lipid binding domains in conjunction with 14-3-3 protein binding. J Biol Chem 2006; 281:17321-36; PMID: 16603546; http://dx.doi.org/10.1074/jbc.M600292200

56. Ayllón V, Fleischer A, Cayla X, García A, Rebollo A. Segregation of Bad from lipid rafts is implicated in the induction of apoptosis. J Immunol 2002; 168:3387-93; PMID:11907096

57. Polzien L, Baljuls A, Roth HM, Kuper J, Benz R, Schweimer K, et al. Pore-forming activity of BAD is regulated by specific phosphorylation and structural transitions of the C-terminal part. Biochim Biophys Acta 2011; 1810:162-9; PMID:21081150; http://dx. doi.org/10.1016/j.bbagen.2010.11.002

58. Rapp UR, Fischer A, Rennefahrt UE, Hekman M, Albert $\mathrm{S}$. BAD association with membranes is regulated by Raf kinases and association with 14-3-3 proteins. Adv Enzyme Regul 2007; 47:281-5; PMID:17336370; http://dx.doi.org/10.1016/j.advenzreg.2006.12.006

59. Renkema GH, Manninen A, Mann DA, Harris M, Saksela K. Identification of the Nef-associated kinase as p21-activated kinase 2. Curr Biol 1999; 9:1407-10; PMID:10607567; http://dx.doi.org/10.1016/S09609822(00)80086-X

60. Nguyen DG, Wolff KC, Yin H, Caldwell JS, Kuhen KL. "UnPAKing" human immunodeficiency virus (HIV) replication: using small interfering RNA screening to identify novel cofactors and elucidate the role of group I PAKs in HIV infection. J Virol 2006; 80: 130-7; PMID:16352537; http://dx.doi.org/10.1128/ JVI.80.1.130-137.2006

61. Xu JW, Ikeda K, Kobayakawa A, Ikami T, Kayano Y, Mitani T, et al. Downregulation of Rac1 activation by caffeic acid in aortic smooth muscle cells. Life Sci 2005; 76:2861-72; PMID:15808886; http://dx.doi.org/10. 1016/j.lfs.2004.11.015

62. Demestre M, Messerli SM, Celli N, Shahhossini M, Kluwe L, Mautner V, et al. CAPE (caffeic acid phenethyl ester)-based propolis extract (Bio 30) suppresses the growth of human neurofibromatosis (NF) tumor xenografts in mice. Phytother Res 2009; 23:226-30; PMID:18726924; http://dx.doi.org/10. $1002 /$ ptr. 2594

63. Messerli SM, Ahn MR, Kunimasa K, Yanagihara M, Tatefuji T, Hashimoto K, et al. Artepillin C (ARC) in Brazilian green propolis selectively blocks oncogenic PAK1 signaling and suppresses the growth of NF tumors in mice. Phytother Res 2009; 23:423-7; PMID: 19003952; http://dx.doi.org/10.1002/ptr.2658

64. Pascua PN, Lee JH, Song MS, Park SJ, Baek YH, Ann $\mathrm{BH}$, et al. Role of the p21-activated kinases (PAKs) in influenza A virus replication. Biochem Biophys Res Commun 2011; 414:569-74; PMID:21982772; http:// dx.doi.org/10.1016/j.bbrc.2011.09.119 